\title{
Corrigendum: Cognitive training with casual video games: points to consider
}

\section{Pauline L. Baniqued ${ }^{1 *}$, Michael B. Kranz ${ }^{1}$, Michelle W. Voss ${ }^{2}$, Hyunkyu Lee $^{3}$, Joshua D. Cosman $^{4}$, Joan Severson ${ }^{5}$ and Arthur F. Kramer ${ }^{1}$}

${ }^{1}$ Department of Psychology, Beckman Institute for Advanced Science and Technology, University of Illinois at Urbana Champaign, Urbana, IL, USA

2 Department of Psychology, University of lowa, lowa City, IA, USA

${ }^{3}$ Brain Plasticity Institute, San Francisco, CA, USA

${ }^{4}$ Department of Psychology, Vanderbilt University, Nashville, TN, USA

${ }^{5}$ Digital Artefacts, LLC, lowa City, IA, USA

${ }^{*}$ Correspondence: banique1@illinois.edu

\section{Edited and reviewed by:}

J. Toby Mordkoff, University of lowa, USA

Keywords: attention, working memory, reasoning, fluid intelligence, video games, cognitive training, casual games, transfer of training

\section{A corrigendum on}

Cognitive training with casual video games: points to consider

by Baniqued PL, Kranz MB, Voss MW,

Lee $H$, Cosman JD, Severson J, et al.

(2014) Front. Psychol. 4:1010. doi:

10.3389/fpsyg.2013.01010

The original publication contained an error that does not impact the significant findings and does not invalidate any conclusions derived from the study. In the WM-REAS 2 group, we inadvertently included data from one subject whose performance in the Attention Network Test (ANT) during post-testing met the exclusionary criteria. This resulted in an exaggerated negative transfer effect for the WM-REAS 2 group. After excluding this subject, the WM-REAS ANT-selective attention (also ANT-visual attention in the original manuscript) data is comparable with the other training groups (Figure 1). The results are consistent after reanalysis, with no significant transfer effect in ANTselective attention $\left[F_{(3,154)}=0.004, p=\right.$ $\left.1.000, \eta_{p}^{2}<0.001\right]$. The reported association between sleep and ANT-selective attention in the original publication is no longer significant $(r=0.177, p=$ $0.310)$. The authors deeply regret this error.

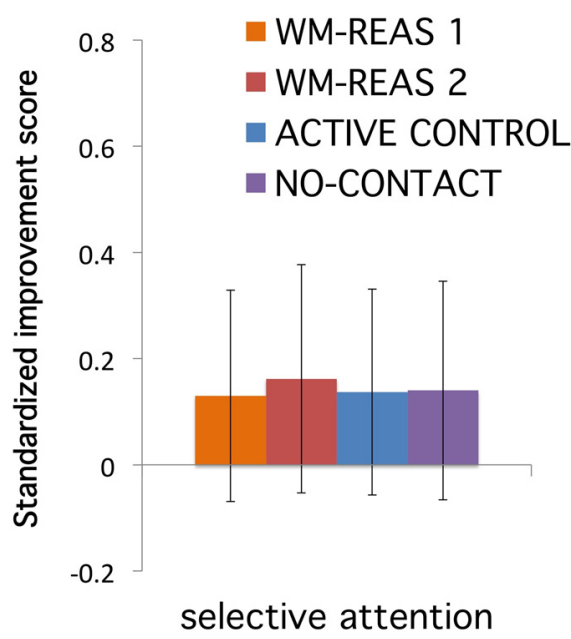

FIGURE 1 | Transfer effects for divided attention.

Received: 18 February 2014; accepted: 02 March 2014; published online: 20 March 2014.

Citation: Baniqued PL, Kranz MB, Voss MW, Lee H, Cosman JD, Severson J and Kramer AF (2014) Corrigendum: Cognitive training with casual video games: points to consider. Front. Psychol. 5:234. doi: 10.3389/fpsyg.2014.00234

This article was submitted to Cognition, a section of the journal Frontiers in Psychology.

Copyright (c) 2014 Baniqued, Kranz, Voss, Lee, Cosman, Severson and Kramer. This is an open-access article distributed under the terms of the Creative Commons Attribution License (CC BY). The use, distribution or reproduction in other forums is permitted, provided the original author(s) or licensor are credited and that the original publication in this journal is cited, in accordance with accepted academic practice. No use, distribution or reproduction is permitted which does not comply with these terms. 